\title{
Cationic Starch Emulsified Beeswax for Enhancing Moisture Barrier of Paper as Packaging Materials
}

\author{
Yuanfeng Pan ${ }^{1,3, a}$, Huining Xiao ${ }^{1, b^{*}}$, Kunqi $\mathrm{Li}^{2, \mathrm{c}}$ and Jixiao $\mathrm{Xu}^{1, \mathrm{~d}}$ \\ ${ }^{1}$ Department of Chemical Engineering, University of New Brunswick, Fredericton, Canada \\ ${ }^{2}$ School of Environment Sci \& Eng.; North China Electrical Power Univ., Baoding, China \\ ${ }^{3}$ Guangxi Key Laboratory of Petrochemical Resource Processing and Process Intensification \\ Technology, School of Chemistry and Chemical Engineering, Guangxi University, Nanning China

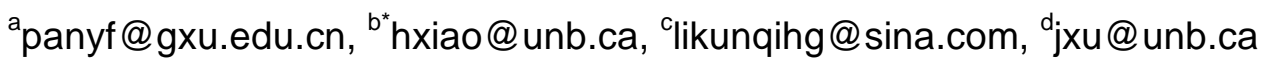

\begin{abstract}
Keywords: cationic starch; latex; cellulose fibre; hydrophobic.
Abstract. Cationic starch was used as an emulsifier to emulsify beeswax into latex, which was utilized for lowering the water vapor transmission rate (WVTR or moisture barrier of the paper used as food packaging materials. The method of wet-end addition was used for applying the emulsions to the papers. The weight ratio of cationic starch to beeswax was mainly investigated as the key factor affecting the particle size of emulsion, adsorption efficiency and WVTR values. The lowest value of WVTR was found to be $460 \mathrm{~g} / \mathrm{m}^{2} \bullet$ day at $38{ }^{\circ} \mathrm{C}$ and $90 \%$ of relative humidity (RH), more than $60 \%$ reduction, compared to that of the untreated blank paper $\left(1180 \mathrm{~g} / \mathrm{m}^{2} \cdot\right.$ day $)$, resulting from the wet-end treatment, which generate green-based and biodegradable packaging materials with improved moisture barrier property.
\end{abstract}

\section{Introduction}

As one of the important starch derivatives, cationic starch is predominately applied in the papermaking industry as a wet-end additive, and also acting as binders in coating process. Introducing cationic starch into papermaking process can increase the various properties of final paper products. With the positive charges, cationic starch can be retained with fibers easily due to electrostatic association; and also assist to enhance the retention of fiber fines, filler and other additives [1]. In recent studies, cationic starch has been used as an emulsifier to develop stable emulsions. In an emulsion system stabilized by cationic starch, cationic starch chains adsorb at the interface between water and oil phases; and a monolayer formed by cationic starch chains envelops the droplet to impede coalescence happening so that the droplets can be finely dispersed in continuous phase [2]. The work presented herein focuses on the emulsification of beeswax using cationic starch, thus creating a green-based latex for enhancing the moisture barrier property of paper as environmental-friendly packaging materials.

\section{Experimental}

Materials. The cationic starch was obtained from Aldrich. Beeswax, with an ivory color, was purchased from Busy Bee Beeswax Company (Tweed, Ontario). Northern bleached softwood Kraft pulps were from Tembec Company.

Preparation of Cationic Starch Stabilizing Beeswax Emulsion. Cationic starch-beeswax emulsions with $10 \mathrm{wt} \%$ cationic starch to beeswax was prepared as follows: $20 \mathrm{~g}$ beeswax, $2 \mathrm{~g}$ cationic starch and $178 \mathrm{~g}$ de-ionized water were placed into a container and then cooked at $90{ }^{\circ} \mathrm{C}$ with a $1000 \mathrm{rpm}$ of homogenizer for 30 minutes.

Particle Size and Distribution of the Latex. Electrophoretic light scattering method, provided by the Particle Size Analysis option of Zeta Potential Analyzer (Model: ZetaPlus) from Brookhaven Instruments Corporation, was used to measure the particle sizes of various cationic starch-emulsions. For each cationic starch-beeswax emulsion, the particle size measurement was run 5 times and an 
effective particle diameter of emulsion was calculated by the analysis software. As an indicator of uniformity of particles in emulsion, the values of polydispersity obtained from the Particle Analyzer were also recorded for a general prediction of particle size distribution.

Employing Emulsion onto Paper. To employ the cationic starch-beeswax emulsions onto/into paper, wet-end addition was applied to fiber slurries or suspension consisting of bleached softwood Kraft pulp prior to preparing handsheets using a standard sheet former. The resulting samples had a dimension of $16 \mathrm{~cm}$ in diameter and $60 \mathrm{~g} / \mathrm{m}^{2}$ in grammage.

Wet-end treated handsheets were prepared from beeswax emulsion with different weight ratios of cationic starch to beeswax $(10 \%, 5 \%$, and $2 \%)$. For the method of wet-end addition, up to $10 \mathrm{wt} \%$ of cationic starch-beeswax emulsion based on dry pulp was added into dilute suspension of fibers during papermaking process, right before the sheet formation. Then the suspension went through a 200 mesh screen; and the water in suspension was drained out. A formatted wet handsheet was left on the mesh screen. The final wet-end treated handsheet was obtained by pressing and hot-plate drying the wet handsheet.

Isotherm Adsorption. For the isotherm adsorption measurement, different amounts of the cationic starch beeswax emulsion were added into the fiber suspension. The concentration of fiber suspension was fixed at $0.1 \%$. The fibers were removed through filtering paper, and the filtrates were held by aluminum plates, drying in oven at $80{ }^{\circ} \mathrm{C}$ for a day and recording the weight changes.

Measurement of WVTR. Water vapor transmission rate (WVTR) was measured using a cup method based on gravimetric balance. The tests were run for all handsheets with the treatments of wet-end addition. All tests were conducted under the condition of $38{ }^{\circ} \mathrm{C}$ of temperature and $90 \%$ of relative humidity.

\section{Results and Discussion}

Particle Size and Uniformity. Figure 1 illustrates how particle size of cationic starch-beeswax emulsion was affected by the amount of cationic starch used to stabilize beeswax emulsion. When the weight ratio of cationic starch to beeswax was raised from $2 \%$ to $5 \%$, the effective particle diameter of cationic starch-beeswax emulsion was decreased from $363 \mathrm{~nm}$ to $230 \mathrm{~nm}$, and the effective particle diameter was then slightly increased to $244 \mathrm{~nm}$ as the weight ratio of cationic starch to beeswax increased to $10 \%$.

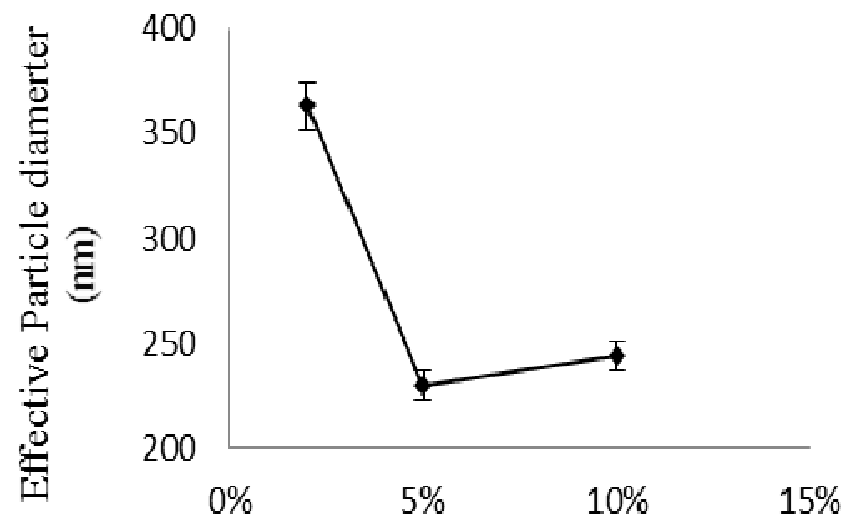

Weight ratio of cationic starch to Beeswax

Fig.1 The relationship between particle size of cationic starch -beeswax emulsion and the weight ratio of cationic starch to beeswax 
Adsorption Efficiency. Adsorption efficiency of cationic starch-beeswax emulsion was studied with respect to time.

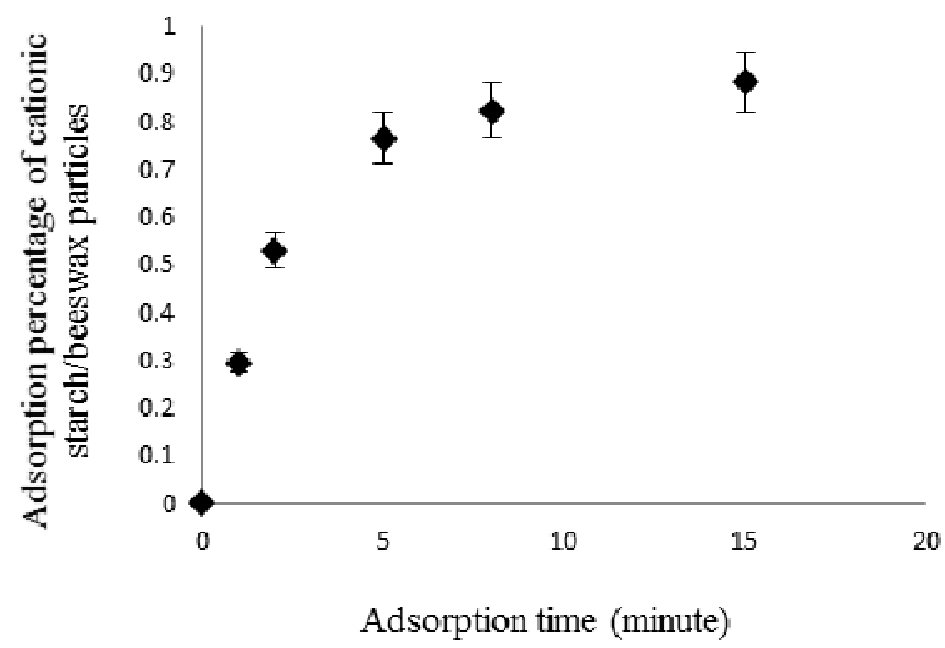

Fig. 2 The correlation between adsorption of cationic starch-beeswax particles and time at Rcationic starch/beeswax $=10 \%$.

The adsorption of cationic starch-beeswax particles was increased with the contacting time for the beeswax emulsion with a $10 \%$ of ratio or Rcationic starch/beeswax, as shown in Figure 2 . The maximum adsorption percentage reached $88.24 \%$ at $\mathrm{t}=15 \mathrm{~min}$.

For the beeswax emulsion with $5 \%$ of Rcationic starch/beeswax, the adsorption percentage of cationic starch-beeswax microspheres onto fibers jumped to around $80 \%$ in the first two minutes and then increased slowly, as described in Figure 3 below. At the end of test, i.e. $t=15$ min, the maximum of adsorption percentage of cationic starch-beeswax particles was achieved, which was close to $100 \%$.

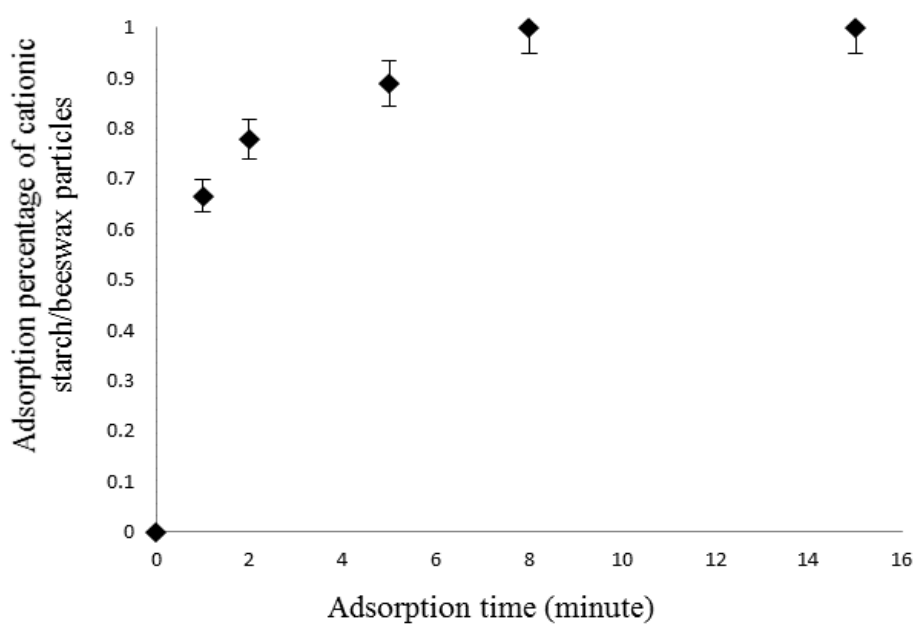

Fig. 3 The correlation between adsorption of cationic starch-beeswax particles and time at Rcationic starch/beeswax $=5 \%$.

The relationship between the adsorption percentage of cationic starch-beeswax particles and the contacting time with fibers for the beeswax emulsion with $5 \%$ of Rcationic starch/beeswax was also investigated. It was found that the adsorption was increased almost linearly with time from the very beginning to $\mathrm{t}=8 \mathrm{~min}$, and grown little in the following seven minutes. The maximum adsorption percentage of cationic starch- beeswax microspheres to cellulose fibers, at $t=15 \mathrm{~min}$, was $72.73 \%$.

Water Vapor Transmission Rate. As displayed in the Figure 4, for the wet-end treatment, the value of WVTR was decreased with the weight ratio of cationic starch to beeswax raised up from $2 \%$ to $10 \%$. 
The WVTR value was determined by the actual amount of beeswax particles retained and filled up the spaces and pores between fibers.

The lowest WVTR value was observed for the handsheet treated by beeswax emulsion with $10 \%$ of Rcationic starch/beeswax, $461 \mathrm{~g} / \mathrm{m} 2 \bullet$ day, followed by $561 \mathrm{~g} / \mathrm{m} 2 \bullet$ day from the emulsion with $5 \%$ of Rcationic starch/beeswax, and the highest value $(603 \mathrm{~g} / \mathrm{m} 2 \cdot$ day) of WVTR was from emulsion with $2 \%$ of Rcationic starch/beeswax. The preliminary results obtained from our work are promising to generate green-based and biodegradable packaging materials.

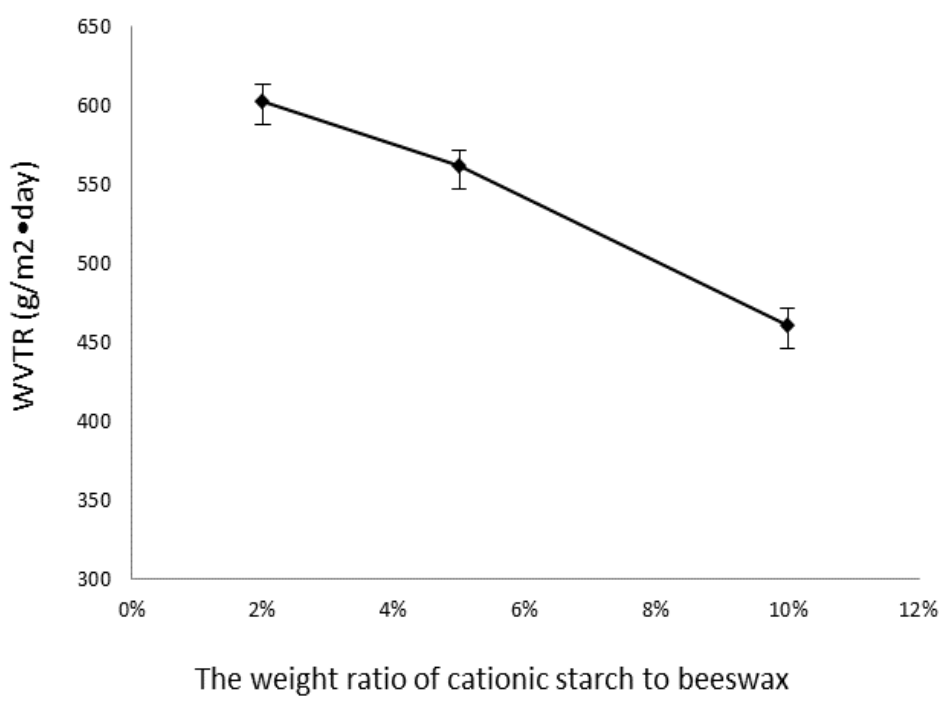

Fig.4 Adsorption isotherms of cationic starch beeswax latexes with different Rcationic starch/beeswax on fibers.

\section{Conclusion}

The particle size of cationic starch-beeswax emulsion was affected by the concentration of cationic starch contained in emulsion: in the moderate concentration of cationic starch, the particle size was decreased with the increase of cationic starch content; and in the region of high concentration of cationic starch when a saturate status has been reached, no more cationic starch adsorbed onto fibers and the excess emulsifier might induce the aggregation of latex particles, and lead to an increase of particle size. The WVTR reduction of paper via wet-end treatment with beeswax was a complex result combining adsorption of cationic starch beeswax particles on to fibers and the retention during the process of draining water out from fiber suspension.

\section{Acknowledgements}

This work was financially supported by NSF China (No. 21466005 and No. 51379077), the NSERC strategic Green Wood Fibre Products network (Canada), Guangxi Natural Science Foundation (No.2014GXNSFAA118036) and the Dean Project of Guangxi Key Laboratory of Petrochemical Resource Processing and Process Intensification Technology (No. 2014Z003).

\section{References}

[1] C. Dong, C.Y. Li, H. Xiao, B. He and L. Qian, beta-Cyclodextrin Grafted Cellulose and Cationic Starch for Antibacterial Paper Products: A Comparative Study, Bioresources 9 (2014) 3580-3590.

[2] H. Lee, J. Shin, C.Koh, H. Ryu, D. Lee and C. Sohn, Surface sizing with cationic starch: its effect on paper quality and papermaking process, TAPPI Journal-Surface Sizing 1 (2002) 1. 